\title{
Más allá de Europa: el expresionismo en la obra de Oswaldo Guayasamín, un análisis comparativo
}

Beyond Europe: Expressionism in the work of Oswaldo Guayasamín, a comparative analysis

Celia Gómez Campos

Departamento de Historia del Arte, Universidad de Málaga, España (celiagcampos@gmail.com)

Recibido el 09 de mayo de 2018; revisado el 20 de junio de 2018; aceptado el 29 de agosto de 2018; publicado el 13 de septiembre de 2018

RESUMEN: El expresionismo es una corriente universal que puede localizarse en diferentes contextos a lo largo de la Historia del Arte, no reduciéndose sólo a un movimiento de vanguardia. Este trabajo busca mostrar cómo esa poética puede surgir en cualquier época y latitud, en la que subyace un trasfondo común. Para ello, se realizará un análisis comparativo entre el expresionismo alemán y el arte moderno latinoamericano, estudiando las semejanzas entre ambos según los parámetros de la temática, la estética y la función del arte. Nos centraremos en Käthe Kollwitz, George Grosz y Otto Dix, por el lado alemán, y en el artista ecuatoriano Oswaldo Guayasamín como paradigma de esta corriente en el ámbito latinoamericano.

PALABRAS CLAVE: expresionismo alemán, expresionismo en América Latina, Oswaldo Guayasamín, Käthe Kollwitz, George Grosz, Otto Dix.

ABSTRACT: Expressionism is a universal movement that can be placed in different contexts throughout art history, but it can't be merely reduced to an Avant-garde movement. This paper seeks to show how this reality can flourish in any age and in any place, in which can be found similar features. To achieve this goal, I will perform a comparative analysis of the German Expressionism and the Latin American Modern Art: similarities between them, the aesthetics and the purpose of art itself. The main focuses of this work are Käthe Kollwitz, George Grosz and Otto Dix, German artists, and, as the paradigm of this movement in the Latin American ambit, the Ecuadorian artist Oswaldo Guayasamín.

KEYWORDS: German Expressionism, Latin American Expressionism, Oswaldo Guayasamín, Käthe Kollwitz, George Grosz, Otto Dix. 


\section{Introducción}

El expresionismo latinoamericano es un tema escasamente analizado. Pese a que muchos autores referencian a algunos artistas como representantes de esta vertiente, a menudo no entran a profundizar en ello. Hay autores que opinan que el Expresionismo alemán no tuvo incidencia en el arte latinoamericano - al igual que otros tantos movimientos de vanguardia—, tal como argumenta Marta Traba (1994: 8). Por otro lado, María Frick defiende la existencia del expresionismo latinoamericano como fruto de la influencia directa con sus semejantes europeos, producida mediante viajes, exilios o exposiciones, adaptando esta corriente a su contexto. En su artículo menciona a los principales exponentes del expresionismo a lo largo de Latinoamérica, aludiendo a los pintores indigenistas ecuatorianos, entre ellos Oswaldo Guayasamín (2014: 128-139).

Es importante delimitar las definiciones del expresionismo. El término más empleado lo concreta como movimiento europeo de vanguardia que tiene su principal foco en Alemania, donde se desarrolla entre 1905 y 1930, surgido como reacción contra el impresionismo (Chilvers, 2001: 269). Sin embargo, es a su vez una poética común a lo largo de la Historia del Arte, localizable en manifestaciones artísticas previas a la existencia del concepto, como afirma Carlos Areán refiriéndose a las obras de Goya o El Greco para definir un expresionismo español ${ }^{1}$. Ian Chilvers presenta esta acepción, definiéndolo como un arte que utiliza "la distorsión y la exageración como recursos para obtener un efecto emocional", que se emplea "para describir el arte sin tener en cuenta el período o lugar, que suscita profundos sentimientos subjetivos por encima de la observación objetiva [...]" (2001: 269). Esta poética no representa a un solo estilo artístico, considerando Donis

A. Dondis que el expresionismo se puede encontrar tanto en el arte gótico y bizantino, como en artistas modernos, pues su finalidad última es provocar un efecto emocional en los espectadores (1976: 59). Para el análisis comparativo nos basaremos en esta última definición, que entiende el expresionismo como una poética que trasciende el propio movimiento germánico tanto geográfica como cronológicamente.

\footnotetext{
${ }^{1}$ Cfr. AREÁN, Carlos (1993). La pintura expresionista en España. Ibérico Europea de Ediciones: Madrid.
} 


\section{Contexto histórico}

El principio del siglo XX europeo es una época de grandes cambios sociales, económicos y políticos, en el que se dan visiones encontradas; por un lado, encontramos una gran fe en el progreso y por otro, se produce un rechazo a la filosofía positivista por considerar que esa sociedad vertiginosa amenaza el estado natural del ser humano y la naturaleza. Esto repercute en la recientemente unificada Alemania bajo el gobierno de Guillermo II, un régimen castrense autoritario que promovía la rápida militarización de la nación. Se formó un ambiente de insatisfacción entre la pequeña burguesía, que veía sus intereses doblegados ante la aristocracia. La competencia imperialista fue creando una burbuja de tensión que unos años más tarde estallaría con la Gran Guerra, dejando a la vista los profundos problemas que sufría Europa y sus contradicciones.

Este ambiente provoca una angustia existencial que se plasma en los precursores del expresionismo: Edvard Munch, Vincent van Gogh y Paul Gauguin. Estos artistas dan forma a la poética del grito, que se acompaña del uso indiscriminado del color y la búsqueda de lo natural y primitivo. Esta visión del mundo y del arte tendrá una gran influencia en los artistas expresionistas.

El expresionismo alemán es un movimiento que, aunque se centra en la pintura, se expande hasta manifestaciones literarias y musicales. Sus representantes principales son los grupos Die Brücke, fundado en 1905 en Dresde por Ernst Ludwig Kirchner, Erich Heckel y otros; y Der Blaue Reiter, fundado 1911 en Munich por Vassily Kandinsky y Franz Marc. En ambos grupos tiene un papel fundamental la espiritualidad, tomando en el primero la forma de la rebeldía y la angustia existencial, y explorando una vertiente mística de introspección y conexión con la divinidad en el segundo.

Más allá de estos grupos germinales del movimiento expresionista, los artistas alemanes en que se sustenta este trabajo son Käthe Kollwitz (1866-1945), Otto Dix (1891-1969) y George Grosz (18931959). Esta elección viene dada porque aportan en su obra una visión angustiosa del individuo, no ya ensimismada, como era común en los artistas de Die Brücke, sino con la realidad de su tiempo en el punto de mira.

Kollwitz destaca por su producción pictórica y gráfica, con un estilo expresionista que posee un marcado tono social de denuncia de las injusticias y representación cruda de la realidad, exaltando el humanismo en una época de ávida industrialización. Plasma la angustia de su época en figuras muy expresivas, con cuerpos distorsionados con los que persigue provocar un efecto en el espectador (Ratjhe y Stockhaus, 2013: 8). 
Tanto Dix como Grosz conocieron las vanguardias de primera mano, experimentando con el expresionismo en una de estas etapas. Participaron en la Primera Guerra Mundial, lo que les dejó recuerdos traumáticos que luego influirían en sus obras, especialmente en las de Dix en su serie Der Krieg (La guerra, 1924).

El expresionismo de estos artistas es el que mejor conecta con la obra de Oswaldo Guayasamín, sobre todo por la temática social y de denuncia presente en ambos focos.

En el plano histórico ecuatoriano encontramos similitudes con el europeo. En 1895 estalló la Revolución liberal, que provocó la guerra civil ecuatoriana entre conservadores y liberales, resultando vencedores estos últimos. Hasta la década de 1940 se da una época de gran inestabilidad política, en la que la industrialización trae consigo el empobrecimiento de las clases bajas y la polarización social.

En el plano artístico, no es hasta la segunda década del siglo XX cuando comienza a cuestionarse el academicismo europeizante que reinaba en la Escuela de Bellas Artes de Quito. Los artistas reciben un gran influjo ideológico de las revoluciones mexicana y rusa, que tendrá su eco en las artes plásticas y la literatura: el estilo más destacado es el realismo social y, dentro de éste, el indigenismo, que muestra la lucha de un pueblo contra su erradicación. El tema indio ya se venía tratando en el arte ecuatoriano desde el XIX de modo costumbrista, idealizado y exótico, pero ahora comienza a verse desde una óptica humanista. Dentro de esta vertiente destacan los ecuatorianos Eduardo Kingman, Diógenes Paredes y Oswaldo Guayasamín (Juan, 2006: 36).

Guayasamín (1919-1999) estuvo muy marcado por su infancia humilde y el asesinato de su joven amigo en una manifestación. A esto se une su ascendencia indígena, que estará siempre presente en su arte, y su empatía con los conflictos bélicos y sociales de su tiempo: guerras mundiales, guerra civil española, dictaduras latinoamericanas, guerra de Vietnam... contra las que enarbola su arte como denuncia (Adoum, 1998: 107). En sus obras encontramos influjo de artistas como Goya, Picasso y José Clemente Orozco, de quien aprendió el arte del muralismo.

\section{Convergencias entre Käthe Kollwitz, George Grosz, Otto Dix y Oswaldo Guayasamín}

La reacción de las vanguardias europeas contra el academicismo hace que se persiga la originalidad en vez de la maestría técnica, lo que genera estilos muy diversos y en ocasiones contradictorios entre 
sí. El Expresionismo alemán ataca al impresionismo por considerarlo vacío de contenido, estancado en lo puramente visual, mientras que los expresionistas buscan transmitir la emoción del pintor y la crítica a su realidad a través de la metáfora del grito. Un contemporáneo del movimiento, el historiador del arte Hermann Bahr, escribiría en 1916 que el artista impresionista "no tiene boca, es incapaz de [...] expresar la ley del espíritu. El expresionista, sin embargo, vuelve abrir la boca de la humanidad, que ya se ha limitado a escuchar suficientemente, callando siempre, y ahora quiere de nuevo propalar la respuesta del espíritu" (Bahr, 1998: 105).

En esa búsqueda de nuevos lenguajes pictóricos, un punto que será común a varias vanguardias será la apropiación del recientemente descubierto arte primitivo africano y oceánico. De él los cubistas extrajeron un aprendizaje esencialmente formal, mientras que, tal como relata De Micheli, los expresionistas resaltaban el valor ritual de las piezas (2002: 63-64). Ante una sociedad que abruma al individuo, girar la mirada hacia lo "salvaje" se vuelve una vía de escape y de conexión espiritual. En esta creación de un arte nuevo que supere lo antiguo, los artistas de ambas latitudes proponen una vuelta a las raíces. Die Brücke busca la identidad resaltando a artistas como Grünewald, Durero o Lucas Cranach el Viejo. Recuperan la xilografía, técnica muy relacionada con el arte popular, que además les permite desarrollar una estética con líneas angulosas que confieren mayor dramatismo a sus imágenes.

En el contex to latinoamericano se busca crear un arte anti-academicista, liberándose de la fuerte influencia europea. Las vanguardias como el expresionismo, el cubismo o el surrealismo tuvieron su eco, pero adaptadas a la idiosincrasia latinoamericana (Aracil y Rodríguez, 1982: 276- 277). De esa forma se va fraguando una conciencia nacional y un estilo propio, dando lugar a movimientos originales que no deben entenderse como un mero trasvase de temas y formas, sino que vuelve la mirada a las raíces americanas precoloniales (Romera, 1974: 6). Esto se manifiesta en la corriente indigenista, que configura una figura idealizada del indio convirtiéndolo en símbolo cultural y protagonista de una Historia de la que siempre había permanecido al margen (Majluf, 1997: 248-251). En este sentido, el muralismo mexicano emplea esta vertiente indigenista con una función política, buscando crear "un lenguaje transparente e inteligible para el hombre y la mujer comunes, y para el proletariado y el campesinado" (Subirats, 2018:224) ${ }^{2}$.

En esa búsqueda de la identidad nacional, Guayasamín viaja por los pueblos de América del Sur, realizando bocetos sobre la cultura y tradiciones de los distintos grupos étnicos: mestizos, indios

\footnotetext{
${ }^{2}$ Eduardo Subirats analiza en profundidad el muralismo mexicano, realizando constantes comparativas entre este movimiento y el expresionismo europeo (remarcando a artistas como Grosz y Dix), pues encuentra entre ambos profundas conexiones discursivas.
} 
y negros. Con ese material realizará la serie Huacayñan (1946-1952), El camino del llanto en lengua quechua, "llanto de resignación y de protesta, de ternura y de sufrimiento, de amor y de cólera, de grito potente e inaudible, que corre por nuestra historia para desbordarse en un presente que es enigma y encrucijada" (Torre Reyes, 1972: 7).

Guayasamín define su obra como expresionista, pero no al modo europeo, sino ahondando en sus raíces precolombinas. En varias ocasiones alude a la influencia que tuvo en sus obras el sitio arqueológico Sechín, Perú (yacimiento del periodo arcaico, c. 2400 a. C.), en cuyos muros se localiza “el expresionismo más antiguo y más vital de la creación plástica, [...] un expresionismo casi abstracto, que corresponde a la mentalidad precolombina, nacido de la entraña más profunda del hombre. Se trata de un expresionismo americano [...]" (Adoum, 1998: 112).

El expresionismo pretende plasmar la cruda realidad y el sufrimiento humano. Se produce un conflicto entre el individuo y su realidad, encontrando en la espiritualidad una vía de escape. Guayasamín explica esa dualidad de angustia interna y externa: "El hombre contemporáneo vive dos dramas, el uno es de piel hacia adentro y el otro de piel para afuera, que al final son solo uno: la angustia del tiempo que nos ha tocado vivir"3. Este conflicto se plasma en una de las temáticas principales del expresionismo, la poética del grito, que maneja el arte como una herramienta para sacar a la luz la ansiedad que oprime al individuo. Esta tensión nos evoca de inmediato al paradigmático cuadro de Edvard Munch. En la obra de Guayasamín el grito es una constante [1], como queda claro en sus elocuentes palabras: "He pintado como si gritara desesperadamente, y mi grito se ha sumado a todos los gritos que expresan la humillación, la angustia del tiempo que nos ha tocado vivir” (Madriñán, 1988: 20).

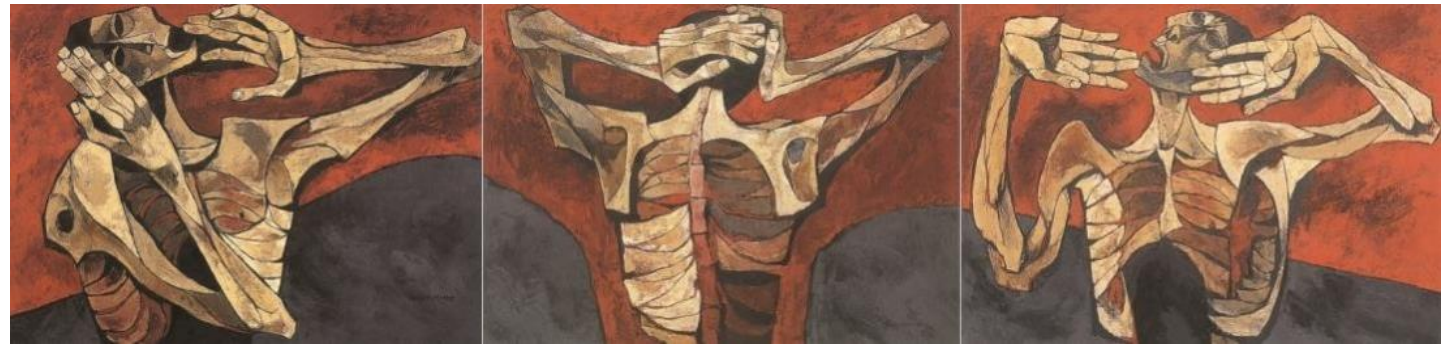

1. Oswaldo Guayasamín, Ríos de Sangre I, II y III, 1986. Óleo sobre lienzo, 137 x 187 cm. cada uno.

\footnotetext{
${ }^{3}$ http://www.guayasamin.org/index.php/oswaldo-guayasamin/frases-de-oswaldo-guayasamin (Consulta: 8-07-18)
} 
Por otro lado, en la obra de los cuatro artistas estudiados subyace una crítica a los poderes socio- económicos que rigen el mundo, un ataque a los autoritarismos, a la explotación de las clases obreras. Esta denuncia a menudo toma forma satírica y burlesca, jugando, mediante la estética expresionista, con la caricatura y la deformación de rostros y cuerpos, consiguiendo con ello un potente impacto visual. Esta categoría estética de lo grotesco la podemos localizar en las series Los culpables (1964-1967) [2] y Reunión en el Pentágono (1966-1970) de Guayasamín. Por su parte, Grosz representa en Los pilares de la sociedad (1926) [3] a los mandatarios militares, económicos y religiosos de un modo caricaturesco y denigrante.

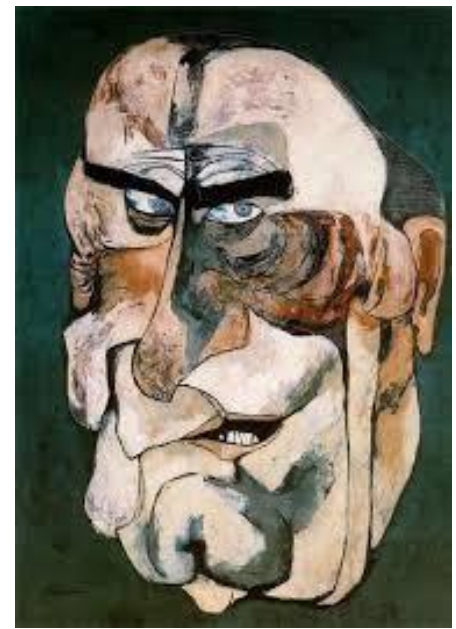

2.

Oswaldo Guayasamín, Los culpables III, El Presidente, serie La edad de la Ira, 1964-1967. Acrílico sobre lienzo, 139 × $101 \mathrm{~cm}$.

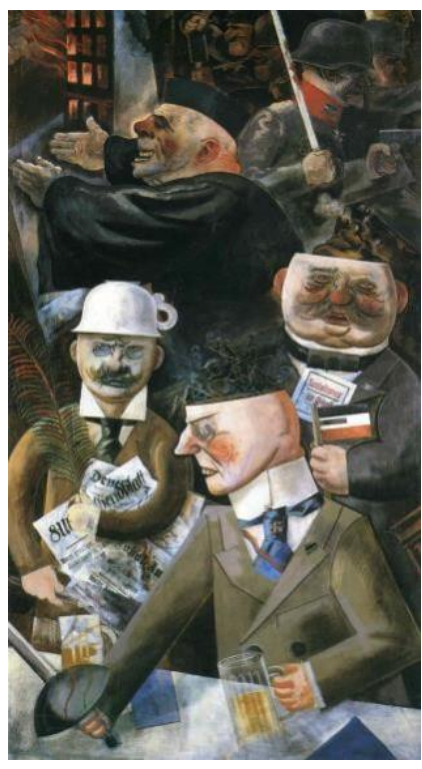

3. George Grosz, Los pilares de la sociedad, 1926. Óleo sobre lienzo. 200 x $108 \mathrm{~cm}$. 
Los conflictos bélicos tuvieron gran repercusión en el elenco de artistas de este estudio. La Primera Guerra Mundial tuvo gran incidencia en los artistas europeos. Algunos se posicionaron a favor de la guerra hasta que vieron lo que ésta suponía, pasando luego a tomar una clara actitud antibelicista. La guerra tuvo eco en sus creaciones artísticas, de tal modo que creadores como Kollwitz, Grosz y Dix "se convirtieron en francos detractores de la guerra y del conflicto armado en general" (Farrell, 2017: 29).

Los aguafuertes de Otto Dix, realizados en su mayoría tras la Primera Guerra Mundial, reflejan con dramatismo las pesadillas del artista. Su conocida serie Der Krieg (La guerra $)^{4}$ muestra la crueldad del conflicto, cadáveres gaseados, soldados mutilados agazapados en trincheras, ruinas... continuando la línea que inició Goya en la representación cruda de los Desastres de la guerra ${ }^{5}$.

Las obras expresionistas muestran con crudeza las consecuencias del conflicto armado, no solo de aquellos que perdieron la vida, sino de aquellos que regresaron a casa con graves secuelas físicas o mentales. Muchos sufrieron mutilaciones, tema que será muy abordado por los artistas expresionistas, como crítica abierta a la guerra y sus consecuencias. Lo vemos en numerosas obras de Dix (entre otras, Los jugadores de cartas, 1920) y también en otras de Guayasamín (mural de Los mutilados, 1976).

Las obras de Käthe Kollwitz muestran un fuerte humanismo y abordan el sufrimiento de las revueltas de los trabajadores, la lucha del campesinado por la subsistencia, la miseria y desesperanza de la época de las guerras mundiales. En sus memorias escribió: “¡Las simientes no deben molerse! Esta exigencia es como decir 'no más guerras'. No es un deseo ardiente, sino mandamiento, exigencia", haciendo una clara alusión a los jóvenes que iban a morir a la guerra (L. F. Cao, 1997: 70). En la serie de xilografías sobre la guerra (Der Krieg, publicada en $1923^{6}$ ) refleja la desolación que dejó a su paso la contienda; pero no habla del campo de batalla, sino de quienes permanecen en sus hogares viendo marchar a sus familiares al frente: madres, viudas, hermanos menores, etc. En su obra hay una clara intención propagandística contra la guerra; Kollwitz perdió a su hijo menor en ella y quiso que esta serie fuese expuesta para mostrar lo cruel de la situación. En la quinta xilografía, Die Freiwilligen (Los voluntarios) [4], con un tono trágico retrata un grupo de jóvenes que marchan

\footnotetext{
${ }^{4}$ Serie completa digitalizada en https://www.moma.org/s/ge/collection_ge/objbytag/objbytag_tag-vo63259_sort-5.html (Consulta: 8/07/18)

${ }^{5}$ Cfr. LÓPEZ HERNÁNDEZ, José Ignacio (2015), "La expresión artística del horror bélico, de Goya a Otto Dix. Estrategias artísticas, fundamentos estéticos, condicionantes éticos.”. Fedro, Revista de Estética y Teoría de las Artes, $\mathrm{n}^{\circ} 15$.

6 Ver la serie completa en https://www.moma.org/s/ge/collection_ge/objbytag/objbytag_tag-vo69682_sort-5.html (Consulta: 8/07/18)
} 
a combatir al ritmo del tambor de la muerte, mientras un grupo de mujeres intenta desesperadamente evitar que emprendan ese viaje quizás sin retorno (Bassie, 2006: 124).

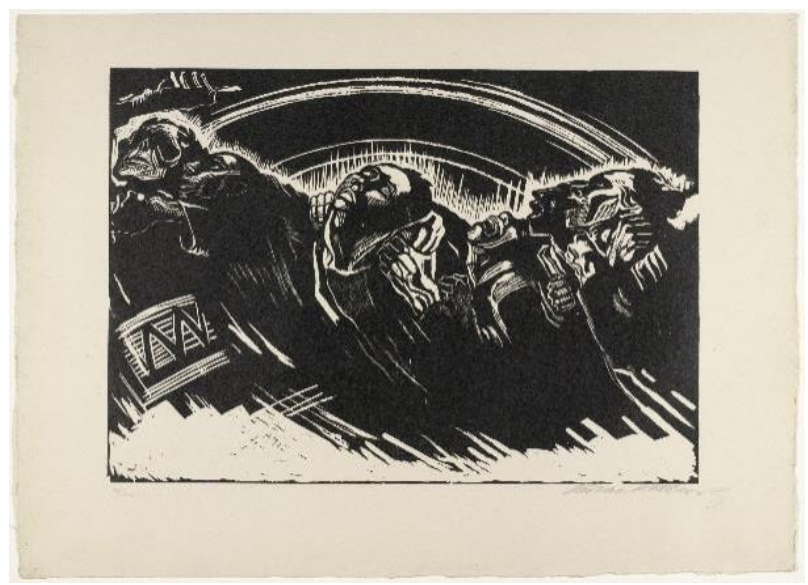

4. Käthe Kollwitz, Die Freiwilligen (Los voluntarios), estampa \#2 de la serie Krieg (Guerra), publicada en 1923. Xilografía, 47.5 x $65.4 \mathrm{~cm}$.

De igual forma, las obras Guayasamín muestran una clara temática social que denuncia la opresión que sufren las clases más bajas americanas, pero trasciende la estética indigenista propiamente dicha para, traspasando las fronteras, proferir un grito contra las masacres en las que el ser humano es a un tiempo verdugo y víctima. De este modo, en su serie La edad de la ira (19521967) lanza un mensaje de solidaridad contra el sufrimiento universal; no retrata los hechos contextualizados, sino que se centra en plasmar, con una visión humanista, las emociones de sus víctimas: su angustia, crispación y terror reflejados en sus cuerpos, confiriendo gran expresividad a los rostros y las manos. Para tal fin emplea un "dibujo rotundo, figuras y rostros descarnados, deformación tremendista, sacrificio de un inicial colorismo por el imperio de los tonos neutros, blancos y negros [...]" (Oña, 1996: 183).

En estas obras alude a los bombardeos de Hiroshima y Nagasaki, el holocausto judío durante el régimen nazi y también refleja la crueldad de la Guerra Civil española en varias de sus obras, destacando la serie Mujeres llorando [5], en la que pinta a doce mujeres que representan el dolor que supone perder en el frente a un ser querido. La temática descarnada se plasma visualmente mediante el empleo de cromatismos reducidos al blanco, negro y gris. Los rostros expresan potentemente el dramatismo de la escena, enfatizado por las manos sobredimensionadas que "se alargan o se crispan, se encogen o se extienden, se repliegan en sí mismas o se abren en la dación total [...].” (Torre 
Reyes, 1972: 24), mientras que el luto negro evoca a esa sombra de la muerte, con una forma que evoca a la del ataúd. El cuerpo expresa sin necesidad de palabras, transmite al espectador la angustia, un grito que traspasa siglos y latitudes.

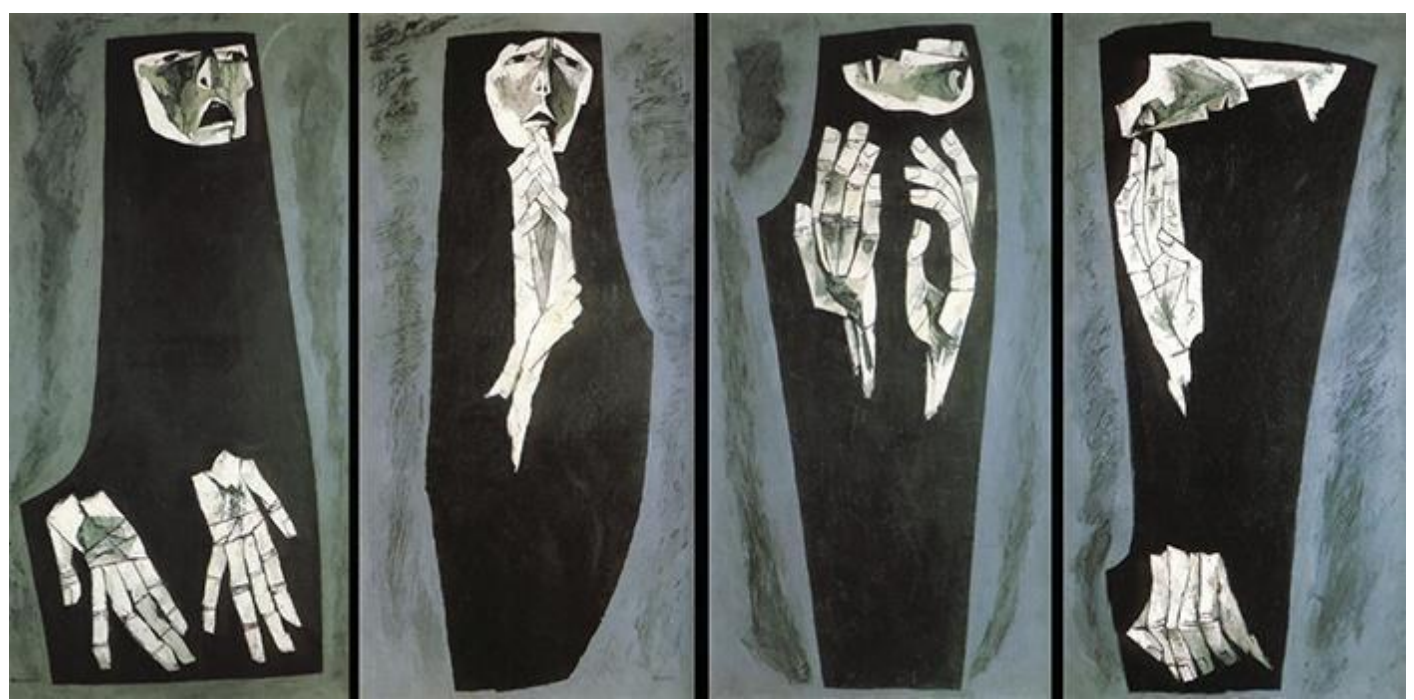

5. Oswaldo Guayasamín, Mujeres llorando IV-VII, serie La edad de la ira, 1963-1965. Óleo sobre lienzo. 145 x $75 \mathrm{~cm}$. cada uno.

\section{Conclusiones}

Más allá de los estudios que niegan la influencia del expresionismo europeo en Latinoamérica y los que defienden su existencia como eco de aquélla, podemos divisar una tercera posición. En Latinoamérica, en concreto en la obra de Oswaldo Guayasamín, se percibe una corriente expresionista de raigambre local, si bien posee influjos del arte moderno europeo. Su obra, como un árbol, ahonda sus raíces en la tierra madre, al tiempo que expande sus ramas hacia la lontananza buscando nuevos estímulos. Por ello, su obra posee una clara originalidad pues, aunque bebe de dos fuentes muy dispares (la tradición y la modernidad), aporta una visión muy personal y humanista sobre el sufrimiento humano.

Tanto Guayasamín como Käthe Kollwitz, George Grosz y Otto Dix acuden al expresionismo para transmitir la angustia de su tiempo, una época muy deshumanizada y violenta, y pretenden con ello despertar conciencias denunciando las atrocidades cometidas en nombre del progreso. El expresionismo nace así como una necesidad, una vía de escape, siendo pues un sentir artístico 
localizable en estos dos focos que, si a simple vista pudieran parecer muy dispares, poseen un trasfondo en el que se dan sendas convergencias.

\section{Referencias bibliográficas}

ADOUM, Jorge Enrique (1998). Guayasamín: el hombre, la obra, la crítica. Editorial Das Andere: Núremberg.

ARACIL, Alfredo y RODRÍGUEZ, Delfín (1982). El siglo XX. Entre la muerte del Arte y el Arte Moderno. Istmo: Madrid.

AREÁN, Carlos (1993). La pintura expresionista en España. Ibérico Europea de Ediciones: Madrid.

BAHR, Hermann (1998). Expresionismo. Editorial Colección de Arquitectura:Murcia.

BASSIE, Ashley (2006). Expresionismo. Numen: México.

BAYÓN, Damián (2006). América latina en sus artes. Siglo Veintiuno Editores: México.

CHILVERS, Ian (2001). Diccionario de Arte. Editorial Complutense: Madrid.

DONDIS, Donis A. (1976). La sintaxis de la imagen: Introducción al Alfabeto Visual. Editorial Gustavo Gil: Barcelona.

FARRELL, Jennifer (2017). World War I and the visual arts. The Metropolitan Museum of Art Bulletin: Nueva York.

FRICK, María (2014), "El expresionismo en la pintura latinoamericana: transferencias y trascendencia”, Atrio, no 20, pp. 128-139.

JUAN, Adelaida de (2006), “Actitudes y reacciones", en BAYÓN, Damián. América latina en sus artes. Siglo Veintiuno Editores: México.

MAJLUF, Natalia (1997). "Nacionalismo e indigenismo en el arte mexicano", en GUTIÉRREZ VIÑUALES, Rodrigo y GUTIÉRREZ, Ramón. Pintura, escultura y fotografía en Iberoamérica, siglos XIX y XX. Cátedra: Madrid.

LÓPEZ FERNÁNDEZ CAO, Marián (1997). Käthe Kollwitz. 1867-1945. Ediciones del Orto: Madrid. 
MADRIÑÁN, Eduardo (dir.) (1988). Guayasamín. El tiempo que me ha tocado vivir. Instituto de Cooperación Iberoamericana: Madrid.

MICHELI, Mario de (2002). Las vanguardias artísticas del siglo XX. Alianza Forma: Madrid.

RATJHE, Gerd y STOCKHAUS Heike (2013). Beyond the borders of existence. Ernst Barlach / Käthe Kollwitz. Museet for Religiøs Kunst: Lemvig.

OÑA, Lenín (1996). "Ecuador”, en SULLIVAN Edward (ed.). Arte Latinoamericano del siglo XX. Nerea: Madrid.

ROMERA, Antonio R. (1974). "Despertar de una conciencia artística (1920-1930)”, en BAYÓN, Damián, América latina en sus artes. Siglo Veintiuno Editores: México.

TRABA, Marta (1994). Arte de América latina. 1900-1980. Banco Interamericano de Desarrollo: Washington.

TORRE REYES, Carlos de la (1972). Guayasamín: Museo Español de Arte Contemporáneo, Madrid, noviembre, 1972. Comisaría de Exposiciones de la Dirección General de Bellas Artes: Madrid.

\section{WEBGRAFÍA}

www.guayasamin.org (Consulta: 8/07/2018)

http://www.guayasamin.org/index.php/obra/la-edad-de-la-ira/199-el-rio-de-la-sangre-i-ii-y-iii-1986 (Consulta: 30/06/2018)

http://espina-roja.blogspot.com/2013/05/los-pilares-de-la-sociedad-de-george.html (Consulta: $15 / 06 / 2018)$

https://www.moma.org/s/ge/collection_ge/objbytag/objbytag_tag-vo69682_sov_sort-5_page-3.html (Consulta: 7/07/18)

http://www.guayasamin.org/index.php/obra/la-edad-de-la-ira/88-mujeres-llorando-i-vii (Consulta: $30 / 06 / 18)$ 